\title{
A NOVEL DAMAGE STATE SIMULATION METHOD WITH SHAPE MEMORY POLYMER
}

Shape Memory Polymer (SMP), a kind of smart materials which can memorize its former shape, has the general character of plastics and rubbers. The paper analyzes the present methods of damage simulation in numerical simulation and model test and performs mechanical test to study SMP's shape memory mechanism as LgE-T. A new thinking is put forward to make the stiffness-controlled specimen according to the deficiency of present simulation methods, which could not simulate the damage process. The validating test proves the stiffness-controlled specimen can simulate the damage process of accumulation and has the value of validating the damage identification and structural safety evaluation algorithms.

Key words: Shape Memory Polymer; damage simulation; stiffness-controlled specimen; safety evaluation

Due to a variety of unforeseen conditions and circumstances, it will never be possible or practical to design and build a structure that has a zero percent probability of failure. Structural aging, environmental impact, and reuse are examples of circumstances that could affect the reliability and the life of a structure [1]. There are needs of periodic inspections to qualify the safety of civil structures in service and take some measures to monitor and evaluate their performance, such as serviceability, reliability, and durability, for the purpose of determining the location, estimating the severity and evaluating the consequences of damage on the structure, if damage has occurred. Since the Aloha Boeing 737 accident [2] that happened on April 28, 1988, such interest has fostered researches in the areas of non-destructive damage identification and structural safety evaluation.

So far, many algorithms have been put forward, such as neural network method, modal flexibility change method, strain energy method and most of these methods have been successfully used to detect the location of certain damage elements, cracks or weld defects, corrosion or erosion [3]. But these algorithms should experience the test of availability verification before they are put into practical application, in which damage state simulation is a key factor. A new thinking of damage state simulation based on Shape Memory Polymer (SMP) is put forward on the analysis of the deficiency of present damage simulation methods, which could not simulate the damage process of occurence and accumulation. The checking result shows this method can regulate the damage degree through temperature adjustment and has the value of practicality.

\section{Structural Damage State Simulation}

\subsection{Description and Consideration of Stiffness as the Damage Factor}

To a multi-freedom degree system, its dynamic equation is defined as follows:

$$
M \ddot{X}+C \dot{X}+K X=f(t)
$$

If damp is ignored, its dynamic eigenvalue is expressed as the following equation:

$$
\left(K-W^{2} \cdot M\right) \cdot \varphi=0
$$

where $M$ is the mass matrix; $C$ is the damp matrix; $K$ is the stiffness matrix; $X$ is the displacement; $f(t)$ is the input impact; $W$ is the vibration frequency; $\varphi$ is the vibration modal.

In the process of damage identification, $W$ and $\varphi$ are tested to judge the severity of damage. Therefore $K$ and $M$ should reveal some change, if damage occurs on the service structure. However when damage forms, such as structural cracks and cross-section cutting occur in real structure, the structural mass distribution generally has minor change, but its stiffness alters greatly, especially to giant structures [4]. Therefore, we always diminish the stiffness of certain parts to simulate the damage state while validating the damage identification and structural safety evaluation algorithms [5].

\footnotetext{
* Du Jian-hua ${ }^{1}$, Zhao Yang-dong ${ }^{2}$

${ }^{1}$ School of Transportation, Shijiazhuang Institute of Railway Technology, 18 Sishuichang Road, Shijiazhuang 050041, China, E-mail: sirtdjh@163.com,

${ }^{2}$ First Branch, CCCC First Highway Consultants Co., Ltd 63 Keji 2nd Road, Xi’an 710075, P. R. China, E-mail: hityangdong@163.com
} 


\subsection{General Methods of Damage State Simulation}

At present, numerical simulation of finite element method and model test are two ways to testify and evaluate the algorithm's validity used in damage identification and structural safety evaluation. To numerical simulation, stiffness-discount is usually used to produce the structural damage state through assuming the decreasing degree of stiffness of certain elements [6]. And during the laboratory or real-structure experiment, some certain kinds of physical methods are adopted to induce the damage state; for example, some parts of a model structure are cut smaller or moved away.

As shown in Fig. 1 and Fig. 2, the cross-section of a bridge model was cut to a certain degree [7] and a vent was introduced in a cantilever bridge model [8], and different degrees of damage state could be created by adjusting the parameters as $t_{1}, t_{2}$ and $h$. Fig. 3 is the famous I-40 bridge I-40 Bridge over Rio Grande in the Albuquerque, New Mexico damage identification test [9]. NMSU, in 1993, introduced four levels of damage (black part) in the middle span of the north plate girder by making various cuts in the web and the flange of the girder. Six kinds of safety monitoring and assessment algorithms were testified in the real-structure experiment.

\subsection{Estimation and Judgment of Simulation Efficiency}

Present simulation methods of damage state mentioned above have great meanings in validating and improving the precision of structural safety evaluation algorithms, but they might not be so effective when applied in a real structure and the potential reasons may be as follows besides an economical aspect:

- The simulated damage state appears as a mutation result and the safety evaluation methods can only be testified under predamage state and step-damage state, therefore it's unable to validate the algorithms in the process of damage accumulation;

- Input loads, such as wind, wave and fluent, are stopped before the physical damage state is introduced in certain parts of the structure, this breaks the verification process and decreases the degree of reliability.

\section{Shape Memory Polymer}

SMP is a special kind of functional materials that could memory its former shape and has the characters of plastics and rubbers, and since the first Shape Memory Polymer, Norborene Polymer, was reported in 1984 by the CDF-Chimie Company in France, many polymers have been studied as SMP, such as polyurethane, cross-linked polystyrene [10].

\subsection{Shape Memory Effect}

SMP could remember its original shape when it is deformed. This means the strain of SMP can be fixed after deformation and then recover almost completely to its original shape under some conditions (i.e. heat, $\mathrm{PH}$ value adjustment, ionic concentration, etc), which is called Shape Memory Effect (SME). Thermally-stimulated SMP is a common kind of shape memory materials.

It is regarded that SME reckons on the specially physical components of SMP, for containing a fixing phase (hard domain) and reversible phase (soft domain).The fixing phase can be chemical and physical cross-links, imparting a level of rigidity, dimensional stability, and thermal resistance, while the reversible phase can be either crystalline or amorphous, and provide properties of elastomers-primarily recovery and energy absorption.

\subsection{Experimental test of Shape Memory Effect}

The SME of SMP materials can be explained by their elastic modulus $(E)$-service temperature $(T)$ character, therefore property test is designed to obtain and classify the relation curve between $E$ and $T$.

Firstly, a II mechanical specimen of 50-mm gauge length is processed with a kind of thermally- stimulated SMP material guided by GB1040-1992 and polished to reduce the influence of stress concentration. Then, the tension test of normal temperature is carried out with testing machine as assistor and electronic extensometer memorizing the transmutation of specimen's gauge at $18.1^{\circ}$ and $20.3^{\circ}$. Then the caloric test is practised from normal

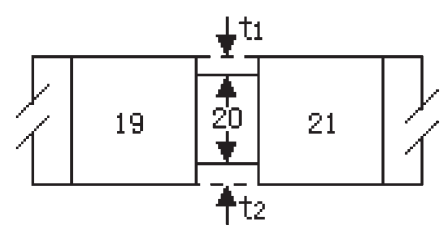

Fig. 1 Cross-section cutting method

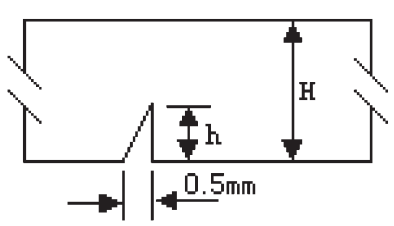

Fig. 2 Vent or crack method

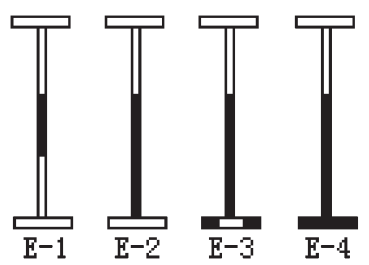

Fig. 3 Four levels of damage state induced in $\mathrm{I}-40$ bridge test 
temperature to about $80^{\circ}$. In this process, heat source is provided by thermal wind with infrared thermo scope registering temperature coordinates. It's noticed that SMP specimen becomes too soft to get précised data with the current instruments when the temperature reaches $60^{\circ}$ or higher, and since the main intention is to measure the vitrification point high level of transmutation of used SMP, and ascertain at which temperature the SMP specimen could be considered to lose its stiffness. Therefore, the reference values manufacturing plant provide are used to describe the relation between $\mathrm{E}$ and $\mathrm{T}$ when the heated temperature is above $60^{\circ}$, and only five representative points of temperature coordinates are recorded in test.

\subsection{Result Analysis}

It can be seen from Fig. 4, the relation graph between $\operatorname{Lg} E$ and $T$ that the elastic ratio of SMP decreases more than two orders of magnitude when heated to the vitrification transition point where the stiffness of SMP could be considered lost. In consequence, we can make a kind of SMP structure and adjust the structure's stiffness to simulate the damage degree by controlling its service temperature and testify the validity of algorithms or programs used for damage identification and safety evaluation.

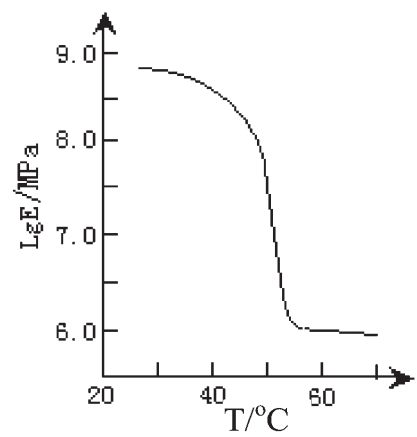

Fig. 4 Test graph of $L g E$ and $T$

\section{Facture of Stiffness-Controlled Specimen}

\subsection{Basic Theory Expression}

For a structure in service, damage only appears in some parts, therefore a certain part of damage is required to reproduce, so SMP can be cut into pieces and glued to the fundal material, such as a polymethy methacrylate (PMMA) pipe. Fig. 5 is the integrated model of SMP and PMMA, whose stiffness is defined as follows:

$$
E A=E_{1} A_{1}+E_{2} A_{2}
$$

where $E_{1}$ and $E_{2}$ are the elastic modulus of SMP and PMMA; $A_{1}$ and $A_{2}$ are corresponding cross-section areas.

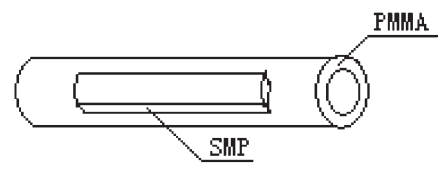

Fig. 5 Glued model of SMP and PMMA

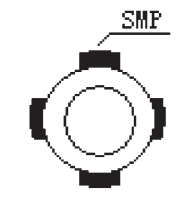

a) Cross-section

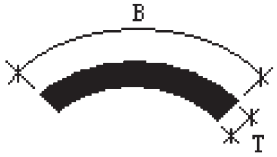

b) Calculation Model
Fig. 6 Width calculation model of SMP

\subsection{Length Calculation of SMP}

Elastic modulus of PMMA, $E_{2}$, varies little when heated to a higher temperature known from its mechanical test result, so its stiffness could be assumed to remain the same at a heated state, and only the stiffness of SMP needs to be considered and regulated.

A kind of thermally-stimulated SMP is cut into four pieces, and $B$, the needed length with a fixed damage degree, could be calculated out from Fig. 6. According to physical and geometric knowledge, $\mathrm{B}$ is determined by the following equation:

$$
\frac{4 E_{1} B T}{E_{2} \frac{\pi\left(R^{2}-r^{2}\right)}{4}}=K
$$

Where $R$ and $r$ are the outer and inner diameters of PMMA; $T$ is a fixed value defined by the thickness of SMP ply; $K$ is a function of the damage degree, $\lambda$ which sticks to the following equation:

$$
K=\frac{\lambda}{1-\lambda}
$$

Suppose the thickness $T$ of $S M P$ ply is $8 \mathrm{~mm}, R$ and pipe wall of PMMA pipe are $34 \mathrm{~mm}$ and $3 \mathrm{~mm}$, so the corresponding $B$ is as Tab. 1 shows.

Length calculation of SMP responding to damage degree

Tab. 1

\begin{tabular}{|c|c|c|c|c|c|c|c|c|}
\hline Volume & \multicolumn{7}{|c|}{ Corresponding value } \\
\hline $\begin{array}{c}\text { Damage degree } \\
\lambda / \%\end{array}$ & 5 & 10 & 15 & 20 & 25 & 30 & 40 & 50 \\
\hline $\begin{array}{c}\text { Length of SMP } \\
\mathrm{B} / \mathrm{mm}\end{array}$ & 1.4 & 3.0 & 4.7 & 6.7 & 8.9 & 11.4 & 17.7 & 26.6 \\
\hline
\end{tabular}




\subsection{Facture of glued specimen}

Here we choose a thermally-stimulated kind of 3.46 mm-thick SMP ply and the fundamental material is a PMMA pipe with $25 \mathrm{~mm}$ outer diameter and $2 \mathrm{~mm}$ thickness pipe wall. Four pieces of SMP are cut into $200 \mathrm{~mm}$-wide and $14 \mathrm{~mm}$-long rectangles. The paste area is granulated to raise the paste force with sand paper and a kind of heat-proved glue water is used to integrate SMP and PMMA pipe together.

Fig. 7 is the picture of stiffness-controlled specimen, whose decreases to $30.9 \%$ when heated to above $60^{\circ}$.

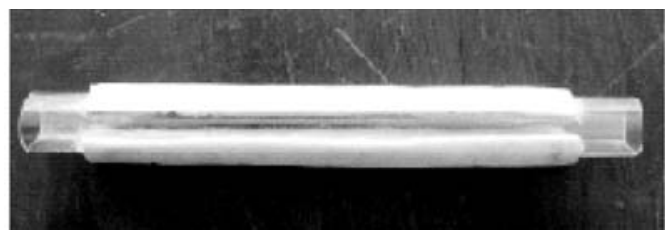

Fig. 7 Picture of glued joint specimen

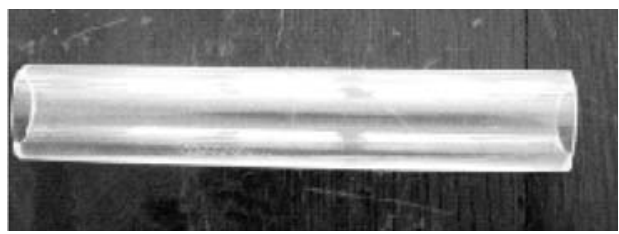

Fig. 8 Poured specimen of futher research

\section{Feasibility Verification}

The cured specimen has been stationed in the room temperature for about 24 hours before its stiffness is measured at a normal state and a heated state and five groups of data have been registered. Tab. 2 is the comparison between the academic analysis value and the test result.
The test damage degree of the SMP specimen is obtained as $29.7 \%$ and it proves a higher precision compared with the academic analysis, but there still exist some relative errors. The possible reasons may be as follows:

- The influence of damp is ignored and it generally increases enhancing the stiffness of SMP specimen at a higher temperature state;

- The SMP material could not lose all the stiffness when heated to the above vitrification transition temperature and the altering of PMMA's stiffness value is not considered;

- The technical conditions, such as heat provision with a heat blower and glued joint need to be enhanced as well as the service precision of test instruments.

\section{Conclusion}

A considerable amount of experience was gained through developing a simulation method of damage state for verifying the validating the feasibility of damage identification and safety evaluation algorithms. The experience has led to the following recommendations:

1. As a kind of smart materials, SMP can memory its former shape which could be explained by its $E-T$ character and the relation graph between $\operatorname{Lg} E$ and $T$ is established through tension test, which shows $60^{\circ}$ is the vitrification transition temperature where to lose the whole stiffness;

2. A new thinking is put forward to feature the stiffness-controllable specimen with SMP affixed to fundus and the verifying test shows the specimen has a more precise ability of damage state simulation;

3. Further research mainly lies in reducing of the vitrification transition temperature of SMP, improving the technique of heatfeature and paste. The poured specimen, as Fig. 8 shows, is worth of particular research.

Comparison of experimental and analysis result

Tab. 2

\begin{tabular}{|c|c|c|c|c|c|c|c|c|c|}
\hline \multirow{2}{*}{ Test state } & \multicolumn{3}{|c|}{ Theoretical result/GPa $\times \mathrm{mm}^{2}$} & \multicolumn{5}{c|}{ Test result/GPa $\times \mathrm{mm}^{2}$} \\
\cline { 2 - 11 } & EASMP & EAPMMA & EA & \multicolumn{3}{c|}{ EA } & Average \\
\hline Normal & 33.55 & 299.42 & 433.62 & 466.74 & 457.64 & 451.58 & 445.52 & 470.78 & 458.5 \\
\hline Heated & 0 & 299.42 & 299.42 & 325.30 & 328.84 & 315.20 & 311.16 & 331.36 & 322.37 \\
\hline
\end{tabular}

\section{References}

[1] CHEN, C. Z., LUO, Y. G., BAI, B. S.: Structural Damage Inspection and Intelligent Diagnosis [M], Bei Jing, Science Press, 2001

[2] OTT JET al. 737 Fuselage Separation Spurs Review of Safeguards [J], Journal of Aviation Week and Space Technology, 1988, 5, 92-95

[3] ROESSET, M. R, JAMES, T., YAO, P.: Application of Structural Health Monitoring and Damage Detection to Marine Systems [C], For Present at the Second World Conference on Structural Control (IWCSC) in Kyoto, Japan, 1998

[4] SHI, Z. Y, LUO, S. X, ZHANG, L. M. et al: Detection of Location and Magnitude of Structural Damage Using Measured Model Data [J], Journal of NUAA, 1997, 29(1), 71-78 
[5] WANG, Z. G, PEI, Y. L., ZHAO, Y. D.: Vibration-Based Damage Detection with Structural Modal Characteristics [J], The Baltic Journal of Road and Bridge Engineering, 2008, (1), 21-28

[6] WANG, S. Q, ZHANG, S. G., LI, H. J.: Study on the Structural Damage Identification Based on the Finite Element Model and Modal Parameters [J], Journal of Ocean University of Qingdao, 2003, 33(4), 650-656

[7] ZHANG, Q. W., SHI, J. J., XIANG, H. F.: Study on the Structural Damage Identification Methods of Bridges [J], Shanghai Municipal Engineering, 1998, 2,1-8

[8] LI, G. Y., ZHENG, H. W.: Study on the Modal Flexibility Analysis of Damage Structure [J], Journal of Vibration, Measurement and Diagnosis, 2002, 22(2),136-152

[9] FARRAR, C. R., BAKER, W. E., BELL, T. M.: Dynamic Characterization and Damage Detection in the I-40 Bridge over Rio Grande [R], Rep, No: LA-12767-MS, Los Alamos National Laboratory, Los Alamos, NM87544

[10] LI, F. K., ZHU, W., ZHANG, X.: Shape Memory Effect of Ethylene-VinyI Acetate Copolymers [J], Journal of Applied Polymer Science, 1999, 71, 1063-1070. 